\title{
The PRO GREENS intervention in Finnish schoolchildren - the degree of implementation affects both mediators and the intake of fruits and vegetables
}

\author{
Reetta Lehto ${ }^{1}$, Suvi Määttä ${ }^{1}$, Elviira Lehto ${ }^{1,2}$, Carola Ray ${ }^{1}$, Saskia te Velde ${ }^{3}$, Nanna Lien $^{4}$, \\ Inga Thorsdottir ${ }^{5}$, Agneta Yngve ${ }^{6}$ and Eva Roos ${ }^{1,2 *}$ \\ ${ }^{1}$ Folkhälsan Research Center, Paasikivenkatu 4, Helsinki 00250, Finland \\ ${ }^{2}$ Department of Public Health, Hjelt Institute, University of Helsinki, Helsinki, Finland \\ ${ }^{3}$ Department of Epidemiology and Biostatistics, EMGO Institute for Health and Care Research, VU University Medical Center, \\ Amsterdam, The Netherlands \\ ${ }^{4}$ Department of Nutrition, The Medical Faculty, University of Oslo, Oslo, Norway \\ ${ }^{5}$ Unit for Nutrition Research, Faculty of Food Science and Nutrition, School of Health Sciences, University of Iceland, \\ Reykjavik, Iceland \\ ${ }^{6}$ School of Hospitality, Culinary Arts and Meal Sciences, Örebro University, Örebro, Sweden
}

(Submitted 7 January 2014 - Final revision received 28 April 2014 - Accepted 11 June 2014 - First published online 8 August 2014)

\section{Abstract}

Little is known about the mediating effects of the determinants of fruit and vegetable (FV) intake in school-based interventions that promote FV intake, and few studies have examined the impact of the degree of implementation on the effects of an intervention. The present study examined whether the degree of implementation of an intervention had an effect on children's fruit or vegetable intake and determined possible mediators of this effect. The study is part of the European PRO GREENS intervention study which aimed to develop effective strategies to promote consumption of fruit and vegetables in schoolchildren across Europe. Data from 727 Finnish children aged 11 years were used. The baseline study was conducted in spring 2009 and the follow-up study 12 months later. The intervention was conducted during the school year 2009-2010. The effects were examined using multilevel mediation analyses. A high degree of implementation of the intervention had an effect on children's fruit intake. Knowledge of recommendations for FV intake and liking mediated the association between a high degree of implementation of the intervention and an increase in the frequency of fruit intake. Knowledge of recommendations for $\mathrm{FV}$ intake and bringing fruits to school as a snack mediated the association between a low degree of implementation of the intervention and an increase in the frequency of fruit intake. Overall, the model accounted for $34 \%$ of the variance in the change in fruit intake frequency. Knowledge of recommendations acted as a mediator between the degree of implementation of the intervention and the change in vegetable intake frequency. In conclusion, the degree of implementation had an effect on fruit intake, and thus in future intervention studies the actual degree of implementation of interventions should be assessed when considering the effects of interventions.

\section{Key words: School-based interventions: Fruits and vegetables: Implementation: Mediation}

Increasing children's fruit and vegetable (FV) intake is of great importance in addressing the childhood obesity epidemic and preventing chronic diseases in adulthood ${ }^{(1,2)}$. School-based interventions to increase children's FV intake have so far had positive effects of varying magnitudes ${ }^{(3-6)}$. To plan and carry out successful school-based interventions, it is vital to know what kind of interventions are effective and why.

Multicomponent interventions are more effective than single-component interventions in which free fruits or vegetables are distributed to children ${ }^{(4,6)}$. Multicomponent interventions that try to influence FV intake should attempt to influence factors that are associated with this behaviour Such factors are, for example, knowledge of recommendations for FV intake, availability and accessibility, taste preferences, a liking for $\mathrm{FV}$, parental modelling, attitudes towards FV and self-efficacy ${ }^{(7-10)}$. In a review of the mediating factors of interventions to improve children's food intake, only attitude and, to a smaller degree, the knowledge of recommendations and self-efficacy have been found to mediate the effect of school-based interventions on changes in FV intake $^{(11)}$. However, few studies have investigated this.

Abbreviation: FV, fruits and vegetables.

*Corresponding author: E. Roos, fax +358 9315 5102, email eva.roos@folkhalsan.fi 
It is also important to study the actual implementation of practical activities that target the selected determinants. The degree of implementation is often found to be far from optimal $^{(12)}$. Implementation means the delivery of the different intervention components according to the intervention plan. The degree of implementation is often influenced by local circumstances in the school and may also be influenced by the level of interest and general workload of the teachers. The assessment of an implementation is usually done using checklists or questionnaires directed at teachers that include questions on the quantity (completeness) and quality (fidelity to instructions) of the implementation ${ }^{(13)}$. The assessment is usually closely tied to the contents of the intervention. It is important to examine the degree of implementation as it has a direct affect on the effectiveness of interventions ${ }^{(14,15)}$.

The aim of the present study was to examine (1) whether the degree of implementation of the PRO GREENS intervention predicted a change in the $\mathrm{FV}$ intake frequency of 10- to 11-year-old schoolchildren in Finland and (2) whether a selection of the potential determinants of FV intake mediated any of the effects of the intervention. We hypothesised that with more exposure to the intervention, the impact on mediators would be stronger and more mediators would be affected and that this would have an impact on FV intake frequency.

\section{Methods \\ Design of the PRO GREENS project}

The present study used Finnish data from the European PRO GREENS project (www.progreens.org ed), which aimed to increase FV intake among 11-year-old children in a school setting. Only Finnish data were used because although the interventions were based on the same plan, each country had its own intervention. The project is based on the Pro Children FV intervention ${ }^{(16)}$. The baseline survey was conducted in May 2009, and follow-up data were collected 1 year later. The intervention was conducted during the school year 2009-2010. The study was approved by the ethics committee of the Department of Public Health of the University of Helsinki.

\section{Finnish sample and data collection}

The sample in Finland was drawn from Swedish-speaking schools that had at least twenty pupils in the fourth and fifth grades, excluding those in the capital region. Only Swedishspeaking schools were recruited because the questionnaires had already been translated into Swedish by the Swedish liaison. The capital region was excluded because a similar intervention had recently been conducted in the relevant schools. All nineteen of the invited schools agreed to participate in the study. All fourth- and fifth-grade teachers $(n 71)$ in the participating schools were asked to participate, and sixty-two agreed. After the baseline study, the nineteen schools were randomised into nine intervention schools (with thirty-two classes) and ten control schools (with thirty classes).
The pupils completed the baseline and follow-up research questionnaires in class under the supervision of their teachers. At the time of the baseline study, the pupils were, on average, 11.4 years old. The participating classes had 1123 pupils, of which 1030 completed the questionnaire. Informed consent was received from 934 parents, and their children comprised the final study participants at baseline, giving a response rate of $83.2 \%$. In the follow-up study, two intervention classes were lost: one did not participate and the other failed to collect the data successfully. Thus, thirty intervention classes (388 children) and thirty control classes ( 424 children) took part in the follow-up study, resulting in a total of 812 children, with an overall response rate of $72.3 \%$. Out of thirty teachers, twenty-four returned a completed questionnaire about the implementation of the intervention during the follow-up study. As only pupils from the intervention classes for which we had the implementation data were included in the analyses, we used data from 727 children, of which 303 were from the intervention classes and 424 from the control classes ( $64.7 \%$ of the original sample).

\section{Intervention}

The intervention was an updated version of the Pro Children intervention, which was reviewed using the Intervention Mapping method ${ }^{(17)}$. Following the review, the intervention was downscaled into four core elements, which were to be implemented in all participating countries. These core elements were classroom sessions on taste and the recommendations for '5 A Day' combined with an assessment of one's own intake, encouragement to bring a snack of fruits or vegetables to school daily and finally a weekly organised fruit/vegetable bring-a-dish event in the class.

In Finland, the intervention lasted from September to the end of April. Before the start of the intervention, a research coordinator visited all the intervention schools. The aims of the visit were to meet the teachers of the intervention classes, motivate them, tell them about the core elements of the intervention, and present the contents of the teacher's manual. During the visit, the teachers received a manual containing instructions for each component of the intervention. The components of the intervention are summarised in Table 1. All the intervention components were performed on the class level, and the class teachers were responsible for the implementation; no school-level actions were taken. The intervention classes also received some posters, and a letter was sent to headmasters, but no other changes were made to the school environment. No fruits or vegetables, other than those included in the normal school lunch, were provided to the children by the schools or the research organisation. All schoolchildren in Finland are provided with a free school lunch that includes salad or raw vegetables daily. Fruits are usually not served. Parents were expected to be involved in the two home assignments and to provide the children with snacks of fruits or vegetables. Teachers kept logbooks about the intervention activities and completed a questionnaire on the implementation of the different intervention components during the follow-up study. 
Table 1. Components of the PRO GREENS intervention in Finland

\begin{tabular}{ll}
\hline Lessons & Other elements \\
\hline Lesson 1: Taste test 1: Senses and basic tastes & Daily fruit/vegetable snacks \\
Lesson 2: Taste test 2: Variation, different fruits and vegetables & Weekly fruit/vegetable bring-a-dish events \\
Lesson 3: Preferences and appreciation for fruits and vegetables & Two home assignments \\
Lesson 4: 5 A Day: How much is it? & Two letters to parents \\
Lesson 5: Recommendations and one's own intake & One letter to the school principal \\
Lesson 6: Goal setting for one's own intake & \\
Lesson 7: How to increase fruit and vegetable intake: Tips for different meals & \\
\hline
\end{tabular}

\section{Measures}

\section{Children's data}

Intake of fruits and vegetables. The intake of $\mathrm{FV}$ was measured using a FFQ that has been validated among children of the same age ${ }^{(18)}$. The intake frequency of fresh fruits, salads or grated vegetables, other raw vegetables and cooked vegetables was assessed with questions having the answer categories never (0), less than once a week (0.25), once a week (1), 2-4 times per week (3), 5-6 times per week (5.5), once per day (7), twice per day (14) and more than twice per day (21). The answers for the intake frequency of all types of vegetables were summed. These were then modified to correspond to the children's FV eating frequency per week (in parentheses above).

Determinants of fruit and vegetable intake. The determinants of FV intake were measured with questions adopted from the reliability-tested questionnaire developed for the Pro Children study ${ }^{(19)}$. The determinants of fruit intake and vegetable intake were assessed separately. All determinants were measured both at baseline and at follow-up. In the present study, the same concepts that were used for the determinants in the Pro Children study were used ${ }^{(19)}$. Knowledge of recommendations was measured using separate questions for fruit intake and vegetable intake: 'How many portions of fruits/vegetables do you think you should eat to have a healthy diet?' The answer categories for these questions were no fruits/vegetables, 1-3 portions/week, 4-6 portions/ week, 1 portion/d, 2 portions/d, 3 portions/d, 4 portions/d and 5 or more portions/d. The answers for fruit intake and vegetable intake were added, and the variable was dichotomised into the categories 'less than 5 portions/d' and ' 5 portions/d or more'. After that, four groups were formed: a decrease in portions from baseline to follow-up; no change from baseline to follow-up (but not 5 times/d or more); an increase in portions from baseline to follow-up (but not 5 times/d or more at follow-up); 5 portions/d or more at follow-up (either an increase in portions from baseline to 5 portions or more at follow-up or 5 portions or more both at baseline and at follow-up). The group with a decrease in portions served as the reference. Liking was assessed using the following statements: 'I like to eat fruits/ vegetables every day' and 'Fruits/vegetables taste good' (Cronbach's $\alpha$ for fruits was 0.69 and for vegetables was 0.85). Self-efficacy was assessed using the following statements: 'It is difficult for me to eat fruits/vegetables every day' and 'If I decide to eat fruits/vegetables every day, I can do it' (Cronbach's $\alpha$ for fruits was 0.48 and for vegetables was $0 \cdot 58$ ). Attitudes were assessed using the following statements: 'To eat fruits/vegetables every day makes me feel good' and 'To eat fruits/vegetables every day gives me more energy' (Cronbach's $\alpha$ for fruits was 0.78 and for vegetables was 0.89 ). The responses to these statements were given on a five-point Likert scale. Taste preference variables were derived from answers for questions on children's taste preferences for fourteen common fruits and berries (two of which were country specific) and sixteen vegetables (four of which were country specific) listed in the questionnaire. The answers for these questions were I like it a lot, I like it, I haven't tasted it, I don't like it and I don't like it at all. Bringing fruits or vegetables to school as a snack represented availability in the present study, as increasing home availability was not an aim of the intervention. The frequency of bringing fruits or vegetables to school as a snack was assessed with the question 'Do you usually bring fruits/vegetables with you to school?' The answers for this question were always, on most days, sometimes, rarely and never.

\section{Teachers' data}

Degree of implementation of the intervention. The degree of implementation of the intervention was determined according to the answers from the teachers' questionnaire administered during the follow-up study. The number of lessons implemented was determined with the open-ended question 'How many lessons have you used to implement PRO GREENS during this school year?' The intake frequency of fruit or vegetable snacks was estimated with the question 'Did you have snack breaks for fruits or vegetables in the class as part of the PRO GREENS project?' Responses were given on a five-point scale ranging from 'yes, on all days' to 'no'. Questions on taste tests, bring-a-dish events and participation in the teachers' info meeting before the intervention were asked. The answers for these questions were 'yes' or

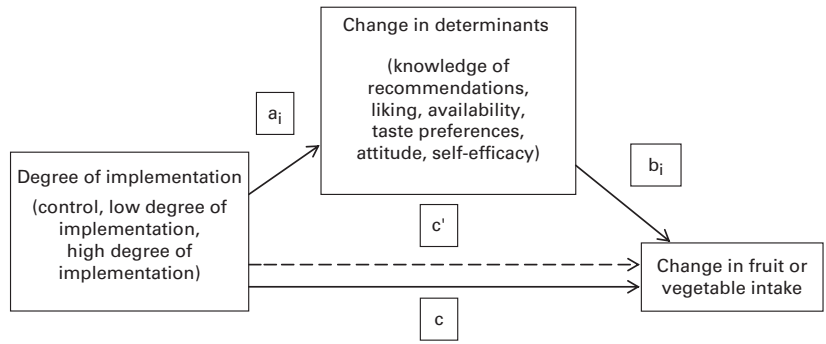

Fig. 1. Conceptual model. 
NS British Journal of Nutrition

Table 2. Descriptive variables of children in the PRO GREENS intervention in Finland

(Mean values and standard deviations; medians and interquartile ranges (IQR))

\begin{tabular}{|c|c|c|c|c|c|c|c|c|c|c|c|c|}
\hline & \multicolumn{4}{|c|}{ Control } & \multicolumn{4}{|c|}{ Low degree of implementation } & \multicolumn{4}{|c|}{ High degree of implementation } \\
\hline & Mean & SD & Median & IQR & Mean & SD & Median & IQR & Mean & SD & Median & IQR \\
\hline$n$ & & & 424 & & & & 130 & & & & 173 & \\
\hline Age (years at baseline) & 11.4 & 0.6 & & & 11.3 & 0.6 & & & 11.5 & 0.6 & & \\
\hline Sex (girls) & & & 48 & & & & 46 & & & & 54 & \\
\hline \multirow{2}{*}{\multicolumn{13}{|c|}{$\begin{array}{l}\text { Fruit and vegetable intake } \\
\text { Fruit intake (times/week) }\end{array}$}} \\
\hline & & \multicolumn{10}{|c|}{ Fruit intake (times/week) } & \\
\hline Baseline & $6 \cdot 1$ & $5 \cdot 3$ & 5.5 & $3 \cdot 0-7 \cdot 0$ & 5.6 & 4.6 & 5.5 & $3 \cdot 0-7 \cdot 0$ & $5 \cdot 1$ & 4.9 & 3.0 & $2 \cdot 5-7 \cdot 0$ \\
\hline Follow-up & $6 \cdot 0$ & $5 \cdot 1$ & 5.5 & $3 \cdot 0-7 \cdot 0$ & $6 \cdot 3$ & 5.5 & 5.5 & $3 \cdot 0-7 \cdot 0$ & $7 \cdot 4$ & $6 \cdot 3$ & 5.5 & $3 \cdot 0-14 \cdot 0$ \\
\hline Significance of change & & & & & & & & & 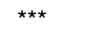 & & & \\
\hline \multicolumn{13}{|l|}{ Vegetable intake (times/week) } \\
\hline Baseline & 11.9 & $9 \cdot 0$ & 9.5 & $6 \cdot 2-14 \cdot 2$ & 11.8 & $7 \cdot 7$ & $10 \cdot 1$ & $6 \cdot 0-16 \cdot 2$ & $10 \cdot 8$ & 7.4 & 9.5 & $6 \cdot 2-14 \cdot 0$ \\
\hline Follow-up & $11 \cdot 1$ & $8 \cdot 2$ & $9 \cdot 3$ & $5 \cdot 0-15 \cdot 5$ & 11.7 & 8.9 & $10 \cdot 3$ & $6 \cdot 2-14 \cdot 0$ & $10 \cdot 6$ & 7.9 & $8 \cdot 8$ & $5 \cdot 0-14 \cdot 0$ \\
\hline \multicolumn{13}{|l|}{ Significance of change } \\
\hline \multirow{2}{*}{\multicolumn{13}{|c|}{$\begin{array}{l}\text { Determinants of fruit intake } \\
\text { Knowledge of recommendations (\%)t }\end{array}$}} \\
\hline \multicolumn{10}{|l|}{ Knowledge of recommendations (\%)† } & & & \\
\hline 1: Decrease from baseline to follow-up & & & 48 & & & & 34 & & & & 21 & \\
\hline 2: Same at baseline and at follow-up & & & 9 & & & & 10 & & & & 4 & \\
\hline 3: Increase from baseline to follow-up & & & 17 & & & & 18 & & & & 23 & \\
\hline 4: Five per day at follow-up & & & 26 & & & & 38 & & & & 52 & \\
\hline \multicolumn{13}{|l|}{ Liking (scale 1 to 5 ) } \\
\hline Baseline & 4.5 & 0.7 & 4.5 & $4 \cdot 0-5 \cdot 0$ & 4.4 & 0.8 & 4.5 & $4 \cdot 0-5 \cdot 0$ & 4.4 & 0.8 & 4.5 & $4 \cdot 0-5 \cdot 0$ \\
\hline Follow-up & 4.4 & 0.8 & 4.5 & $4 \cdot 0-5 \cdot 0$ & $4 \cdot 3$ & 0.8 & 4.5 & $4 \cdot 0-5 \cdot 0$ & 4.4 & 0.7 & 4.5 & $4 \cdot 0-5 \cdot 0$ \\
\hline Significance of change & * & & & & & & & & & & & \\
\hline \multicolumn{13}{|l|}{ Fruits to school (scale 1 to 5 ) } \\
\hline Baseline & $2 \cdot 4$ & 1.0 & $2 \cdot 0$ & $2 \cdot 0-3 \cdot 0$ & $2 \cdot 4$ & $1 \cdot 1$ & $2 \cdot 0$ & $2 \cdot 0-3 \cdot 0$ & $2 \cdot 3$ & 1.0 & $2 \cdot 0$ & $1 \cdot 3-3 \cdot 0$ \\
\hline Follow-up & $2 \cdot 2$ & 1.0 & $2 \cdot 0$ & $1.0-3.0$ & 2.5 & $1 \cdot 2$ & $2 \cdot 0$ & $2 \cdot 0-3 \cdot 0$ & $2 \cdot 6$ & 1.2 & $2 \cdot 0$ & $2 \cdot 0-3 \cdot 0$ \\
\hline Significance of change & 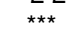 & & & & & & & & 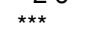 & & & \\
\hline \multicolumn{13}{|l|}{ Taste preferences (scale -2 to 2 ) } \\
\hline Baseline & 1.4 & 0.5 & 1.5 & $1 \cdot 1-1.7$ & 1.4 & 0.6 & 1.5 & $1.1-1.8$ & 1.4 & 0.5 & 1.5 & $1.3-1.7$ \\
\hline Follow-up & 1.4 & 0.6 & 1.5 & $1 \cdot 1-1.8$ & 1.4 & 0.6 & 1.6 & $1 \cdot 1-1 \cdot 8$ & 1.4 & 0.5 & 1.5 & $1 \cdot 3-1.7$ \\
\hline \multirow{2}{*}{\multicolumn{13}{|c|}{$\begin{array}{l}\text { Significance of change } \\
\text { Attitude (scale } 1 \text { to } 5 \text { ) }\end{array}$}} \\
\hline \multicolumn{10}{|l|}{ Attitude (scale 1 to 5 ) } & & & \\
\hline Baseline & $4 \cdot 2$ & 0.8 & 4.0 & $4 \cdot 0-5 \cdot 0$ & $4 \cdot 1$ & 0.8 & 4.5 & $3 \cdot 8-5 \cdot 0$ & 4.0 & 0.9 & 4.0 & $3.5-4.5$ \\
\hline Follow-up & $4 \cdot 1$ & 0.9 & 4.0 & $3.5-5 \cdot 0$ & 3.9 & $1 \cdot 1$ & 4.0 & $3.5-5.0$ & 4.0 & 0.8 & 4.0 & $3.5-4.5$ \\
\hline Significance of change & ** & & & & ** & & & & & & & \\
\hline \multicolumn{13}{|l|}{ Self-efficacy (scale 1 to 5 ) } \\
\hline Baseline & 4.2 & 0.8 & 4.5 & $3.5-5.0$ & 4.2 & 0.9 & 4.5 & $3.5-5.0$ & $4 \cdot 1$ & 1.0 & 4.5 & $3.5-5.0$ \\
\hline Follow-up & 4.2 & 0.8 & 4.5 & $3 \cdot 5-5 \cdot 0$ & 4.2 & 0.9 & 4.5 & $3 \cdot 5-5 \cdot 0$ & 4.2 & 0.8 & 4.5 & $4 \cdot 0-5 \cdot 0$ \\
\hline \multicolumn{13}{|l|}{ Significance of change } \\
\hline \multicolumn{13}{|l|}{ Determinants of vegetable intake } \\
\hline \multicolumn{13}{|l|}{ Liking (scale 1 to 5 ) } \\
\hline Baseline & 3.8 & 1.0 & 4.0 & $3.0-4.5$ & $3 \cdot 7$ & 1.0 & 4.0 & $3 \cdot 0-4.5$ & 3.5 & $1 \cdot 2$ & 4.0 & $2.5-4.5$ \\
\hline Follow-up & 3.6 & $1 \cdot 1$ & 4.0 & $3.0-4.5$ & 3.6 & 1.0 & 3.5 & $3.0-4.5$ & 3.5 & $1 \cdot 2$ & 3.5 & $2.5-4.5$ \\
\hline Significance of change & $* * *$ & & & & & & & & & & & \\
\hline Vegetables to school (scale 1 to 5 ) & & & & & & & & & & & & \\
\hline Baseline & 1.9 & 0.9 & $2 \cdot 0$ & $1 \cdot 0-3 \cdot 0$ & 1.8 & 1.0 & 1.0 & $1 \cdot 0-2 \cdot 0$ & 1.7 & 0.9 & 1.0 & $1 \cdot 0-2 \cdot 0$ \\
\hline Follow-up & 1.7 & 0.8 & 1.0 & $1 \cdot 0-2 \cdot 0$ & 1.9 & $1 \cdot 1$ & $2 \cdot 0$ & $1 \cdot 0-3 \cdot 0$ & 1.8 & 0.9 & $2 \cdot 0$ & $1 \cdot 0-2 \cdot 0$ \\
\hline Significance of change & 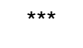 & & & & & & & & & & & \\
\hline
\end{tabular}


'no'. The answers were then summed. Each 'yes' answer received 1 point and the answers for questions on the number of lessons implemented and the intake frequency of fruit snacks each received $0-3$ points with a maximum of 9 points. To examine the group of children who received a large proportion of the intervention, the intervention classes were divided into two groups: the group with a high degree of implementation where the teachers had a total of 5-9 points and the group with a low degree of implementation where the teachers had $0-4$ points. The control schools served as the reference group.

\section{Statistical analyses}

Sample size calculations of the PRO GREENS study have been published elsewhere ${ }^{(20)}$. Means, standard deviations and percentages are used to describe the characteristics of the study sample. As the variables were not normally distributed, medians and interquartile ranges are also reported. Spearman's correlations between the measured variables were checked. These calculations were carried out using SPSS 19 software (SPSS, Inc.).

To examine whether the degree of implementation of the intervention predicted a change in fruit intake and in vegetable intake and whether a selection of the potential determinants of $\mathrm{FV}$ intake mediated any of the effects of the intervention, multilevel mediation analyses were conducted $^{(21)}$. Mediation analysis estimates and tests the hypotheses about the paths of causal influence from an independent variable on an outcome, through one or more proposed intervening variable(s) (the mediator, indirect path) and a second variable independent of the intervening mechanism (direct path). The multilevel design takes into account that the units of observation are nested under a higher-level unit. In the present study, the intervention was conducted in a classroom and led by a teacher. Children in the same classroom might be more similar to each other than children from other classrooms.

The proposed mediation model (Fig. 1) was examined using Mplus statistical software version $7.0^{(21)}$. Maximum likelihood robust was used as the estimation method. Maximum likelihood robust produces standard errors by means of a sandwich estimator, which has been shown to be robust to non-normality and non-independence of the observations ${ }^{(21)}$. The model fit was not evaluated because the estimated multilevel mediation model was saturated. The bootstrapping method was used to determine the $95 \%$ CI. For the multilevel mediation model, two dummy variables (a low degree of implementation and a high degree of implementation) were created for the three-group categorical independent variable, treating the control group as the reference category. Residual change variables of the mediators were used. The outcome was the fruit or vegetable intake at follow-up. Age, sex and $\mathrm{FV}$ intake at baseline were adjusted for in the analyses.

The conceptual model of the analyses (Fig. 1) can be divided into five phases: (1) the impact of the degree of implementation on the change in determinants (a path); (2) the impact of changes in determinants on the change in 
Table 3. Number and percentage of teachers who implemented different components of the PRO GREENS intervention in Finland in groups defined by the overall degree of implementation of the intervention

\begin{tabular}{|c|c|c|c|c|c|c|}
\hline & \multicolumn{2}{|c|}{$\begin{array}{l}\text { Low degree of } \\
\text { implementation } \\
\quad(n 14)\end{array}$} & \multicolumn{2}{|c|}{$\begin{array}{l}\text { High degree of } \\
\text { implementation } \\
(n 10)\end{array}$} & \multicolumn{2}{|c|}{$\begin{array}{c}\text { Total } \\
\text { number } \\
(\%)(n 24)\end{array}$} \\
\hline & $n$ & $\%$ & $n$ & $\%$ & $n$ & $\%$ \\
\hline $\begin{array}{l}\text { Lessons (at } \\
\text { least seven) }\end{array}$ & 1 & 7 & 9 & 90 & 10 & 42 \\
\hline $\begin{array}{l}\text { Fruit/vegetable } \\
\text { snacks (at } \\
\text { least once } \\
\text { a week) }\end{array}$ & 4 & 29 & 5 & 50 & 9 & 33 \\
\hline $\begin{array}{l}\text { Bring-a-dish } \\
\text { breaks (yes) }\end{array}$ & 7 & 50 & 10 & 100 & 17 & 71 \\
\hline Taste tests (yes) & 6 & 43 & 10 & 100 & 16 & 67 \\
\hline $\begin{array}{l}\text { Research } \\
\text { coordinator } \\
\text { meeting (yes) }\end{array}$ & 10 & 71 & 9 & 90 & 19 & 79 \\
\hline
\end{tabular}

fruit or vegetable intake at follow-up (b path); (3) the impact of the degree of implementation on changes in fruit or vegetable intake (c path or total effect); (4) the impact of the degree of implementation on changes in fruit or vegetable intake with adjustments made for all mediators ( $c^{\prime}$ path or direct effect); (5) the impact of the degree of implementation on changes in fruit or vegetable intake through changes in mediators $(\mathrm{a} \times \mathrm{b}$ path or indirect effect). These phases were first separately conducted for each proposed mediator. After that, a multiple-mediator model with significant mediators from the single-mediator models was evaluated. The analyses were carried out separately for fruit intake and vegetable intake.

\section{Results}

\section{Descriptive statistics}

The frequency of fruit intake increased from baseline to follow-up in the group with a high degree of implementation of the intervention, but no other changes in the frequency of fruit or vegetable intake from baseline to follow-up were observed (Table 2). Bringing fruits to school as a snack increased in the group with a high degree of implementation, as did the knowledge of recommendations. Other changes in the determinants of FV intake were negative and occurred mostly in the control group. The number and percentage of teachers who implemented different components of the intervention are summarised in Table 3. The correlations between the changes in the mediating variables were weak, as were those between the changes in the mediating variables and the degree of implementation of the intervention (Table 4).

\section{Mediation analyses}

Fruit intake. Changes in the knowledge of recommendations, liking and bringing fruits as a snack to school were significant mediators, when the single-mediator models for fruit intake were examined. Therefore, knowledge of recommendations, bringing fruits as a snack to school and liking were chosen for the final multiple-mediator model.

The total effect of a high degree of implementation of the intervention on the change in fruit intake was significant (c path: 1.89, 95\% CI 0.26, 3.52), whereas the total effect of a low degree of implementation of the intervention was not significant (c path: $0.64,95 \%$ CI $-0.43,1.71$ ). The path coefficients and standard errors for the multiple-mediator model are shown in Fig. 2. Both low and high degrees of implementation of the intervention were significantly associated with a change in the knowledge of recommendations and availability, as was bringing fruits to school as a snack, whereas only a high degree of implementation of the intervention was significantly associated with a change in liking (a path). The associations were stronger for a high degree of implementation than for a low degree of implementation. Changes in the knowledge of recommendations, bringing fruits as a snack to school and liking were significantly associated with a change in fruit intake (b path). The direct effect of both high and low degrees of implementation of the intervention on the change in fruit intake was not significant ( $c^{\prime}$ path). Overall, the model was significant and accounted for $34.3 \%$ of the change in fruit intake.

The total indirect effect and specific indirect effects are summarised in Table 5. The total indirect effect of the low and high degrees of implementation on the change in fruit intake through knowledge of recommendations and liking were significant. The specific indirect effect of bringing fruits to school as a snack from a low degree of implementation of the intervention on the change in fruit intake was significant. The specific indirect effects of change in the knowledge of recommendations and change in liking from a high degree of implementation of the intervention on the change in fruit intake were significant.

Vegetable intake. Knowledge of recommendations was a significant mediator when the single-mediator models for the change in vegetable intake were evaluated. The total effect of both low and high degrees of implementation of the intervention on the change in vegetable intake was not significant (low degree of implementation: 0.65 , 95\% CI - 0.87, 2.17; high degree of implementation: $-0 \cdot 07,95 \% \mathrm{CI}-2 \cdot 03,1 \cdot 90)$. Both high $(0.90,95 \%$ CI $0.04,0.77)$ and low (0.40, $95 \%$ CI $0.60,1.19)$ degrees of implementation of the intervention were significantly associated with a change in the knowledge of recommendations (a paths). Change in the knowledge of recommendations was significantly associated with a change in vegetable intake (b path: $1 \cdot 27,95 \% \mathrm{CI} 0 \cdot 78,0 \cdot 76$ ). The indirect effect of change in the knowledge of recommendations was significant (Table 5).

\section{Discussion}

The present study examined whether changes in the knowledge of recommendations, bringing fruits or vegetables to school as a snack, liking, taste preferences, attitudes and self-efficacy mediated the association between the degree of implementation of a school-based FV intervention and a change in FV intake frequency. When compared with the con- 
trol group, both low and high degrees of implementation of the intervention predicted an increase in fruit intake via a change in the knowledge of recommendations, but a high degree of implementation showed a stronger effect. Liking, on the other hand, acted as a mediator only between a high degree of implementation and a change in fruit intake, and bringing fruits to school as a snack acted as a mediator only between a low degree of implementation and a change in fruit intake. Only the knowledge of recommendations mediated the association between the degree of implementation of the intervention and a change in vegetable intake, but no direct effect on the change in vegetable intake was found in the study.

The outcome in the present study was FV intake. The intake of fruits was quite low among the children in the present study. This result is, however, in line with the results of previous population studies among Finnish schoolchildren. The Health Behaviour in School-aged Children (HBSC) study reported that among 11-year-olds from forty-one countries in Europe and North America, Finnish children had almost the lowest level of daily fruit intake ${ }^{(22)}$.

Few intervention studies have examined the relevance of the degree of implementation of a FV school-based intervention to its results. In concordance with these earlier studies $^{(14,15,23)}$, we found that the degree of implementation is important as fruit intake increased only in the group with a high degree of implementation. Thus, when assessing the results of an intervention, the degree of implementation should be taken into account.

The degree of implementation was assessed only according to quantity (dose) and other potentially important aspects of implementation, as fidelity to the intervention plan, participant responsiveness and programme differentiation are not known ${ }^{(24)}$. Implementation of the intervention was generally quite low. The reasons for this were not covered in the present study, but lack of time, low self-efficacy and motivation, and organisational issues in the class and in the school might have had an impact ${ }^{(12)}$. Involving teachers in the planning of the intervention could increase their motivation, but this was not done in this case.

The knowledge of recommendations was found to act as a mediator of FV intake in one school intervention that aimed to increase FV intake ${ }^{(25)}$, but only in a subsample. In two other studies, no mediation effect was found ${ }^{(26,27)}$, although the knowledge of recommendations satisfied the conditions for mediation analysis in both studies (the intervention was associated with a change in knowledge, which in turn was associated with a change in fruit/vegetable intake). Among adults, the knowledge of recommendations has been found to mediate the association between an intervention and a change in $\mathrm{FV}$ intake ${ }^{(28)}$.

Bringing fruits to school as a snack mediated the intervention effect, but only in the group with a low degree of implementation, which was an unexpected result. A reason for this can be that in the group with a high degree of implementation other components of the intervention overrode the effect of bringing fruits to school as a snack and the children in that group increased their intake by other 


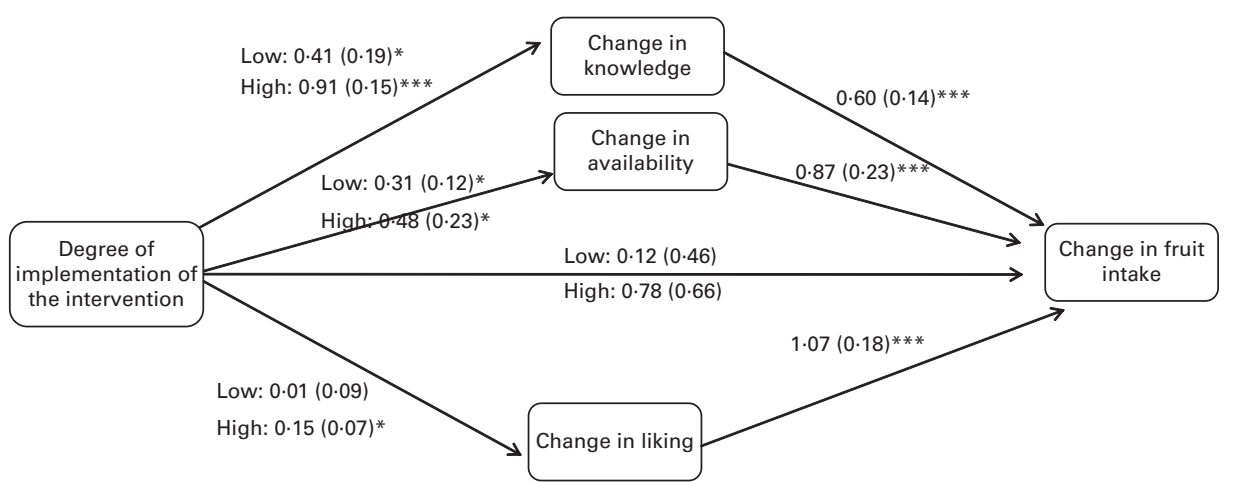

Fig. 2. Coefficients representing the effects (and standard errors) of the degree of implementation of the intervention on the change in mediators and change in fruit intake adjusted for sex and baseline fruit intake in the multiple-mediator model (a, b and $c^{\prime}$ paths) ( $n$ 708). The association was statistically significant: ${ }^{*} P<0.05,{ }^{* * *} P<0.001$.

means. Availability has not been found to mediate FV intake in earlier studies ${ }^{(25)}$, although availability and accessibility are known to be associated with fruit intake ${ }^{(7,29)}$. Knowledge and availability might have been effective because bringing FV to school as snacks was an important part of the intervention and having an impact on the level of knowledge may be easier than changing taste preferences. Liking was a mediator in the group with a high degree of implementation. This may indicate that a more intensive implementation in general or some specific components of the intervention carried out in the group with a high degree of implementation had an effect on liking. No earlier results on liking as a mediator have been reported.

Many of the assumed mediators did not act as mediators between the degree of implementation of the intervention and a change in fruit intake. One of the aims of the intervention was to influence taste preferences, but liking did not emerge as a mediator in our analyses. The $b$ paths of all the assumed mediators were significant, meaning that an increase in these determinants had a positive effect on the change in fruit intake, but the intervention had no effect on these determinants. More time or more intensive interventions may be needed to have an effect on these variables.

Although no total effect on children's vegetable intake frequency was found, the mediation analyses indicated that a change in the knowledge of recommendations mediated an association between the degree of implementation and a change in vegetable intake. Because the same knowledge variable also acted as a mediator for a change in fruit intake, interventions should focus on promoting knowledge of the recommendations. The lack of an effect on vegetable intake in the present study is hard to compare with other studies. In one previous study, fruit intake and vegetable intake were studied together ${ }^{(25)}$. Furthermore, liking for vegetables, taste preferences, attitudes and knowledge have been found to be associated with daily vegetable intake ${ }^{(7)}$. Other FV interventions have also found that increasing vegetable intake is more challenging than increasing fruit intake in children ${ }^{(5,6)}$. As eating occasions for FV differ and vegetables are usually eaten at meals, convincing those who cook for children,

Table 5. Total indirect and specific indirect effects* of the degree of implementation of the intervention on the change in fruit and vegetable intake among 11-year-old children in the PRO GREENS intervention in Finland $†$ ( $\beta$-Coefficients, standard errors and $95 \%$ confidence intervals, $n 708$ )

\begin{tabular}{|c|c|c|c|c|}
\hline & Degree of implementation of the intervention & $\beta$-Coefficient & SE & $95 \% \mathrm{Cl}$ \\
\hline \multicolumn{5}{|l|}{ Fruit intake } \\
\hline \multirow[t]{3}{*}{ Total indirect effect } & Control & 0 & & \\
\hline & Low degree of implementation & 0.52 & 0.24 & $0.05,0.99$ \\
\hline & High degree of implementation & $1 \cdot 11$ & 0.34 & $0.35,1.87$ \\
\hline \multirow[t]{3}{*}{ Knowledge } & Control & 0 & & \\
\hline & Low degree of implementation & 0.24 & 0.14 & $-0.03,0.24$ \\
\hline & High degree of implementation & 0.54 & 0.17 & $0.21,0.54$ \\
\hline \multirow[t]{3}{*}{ Availability } & Control & & & \\
\hline & Low degree of implementation & 0.27 & 0.13 & $0.02,0.52$ \\
\hline & High degree of implementation & 0.42 & 0.27 & $-0.11,0.94$ \\
\hline \multirow[t]{3}{*}{ Liking } & Control & 0 & & \\
\hline & Low degree of implementation & 0.01 & 0.09 & $-0.18,0.19$ \\
\hline & High degree of implementation & 0.16 & 0.07 & $0.02,0.30$ \\
\hline \multicolumn{5}{|l|}{ Vegetable intake } \\
\hline \multirow[t]{3}{*}{ Knowledge } & Control & & & \\
\hline & Low degree of implementation & 0.51 & 0.26 & $0.01,1.02$ \\
\hline & High degree of implementation & $1 \cdot 14$ & 0.31 & $0.53,1.74$ \\
\hline
\end{tabular}

* Through changes in knowledge, availability and liking for fruit intake and change in knowledge for vegetable intake. †Adjusted for sex and age. 
namely parents and school lunch providers, to increase children's vegetable intake may achieve better results. The situation in Finland might differ from that in some other countries, as all children receive vegetables as part of the free school lunch. Still, interventions that have tried to influence parents and increase the home availability of vegetables have not achieved any more promising results ${ }^{(5,6)}$.

The present study has both strengths and weaknesses. Few mediation studies and studies that have examined the impact of the degree of implementation of a school-based intervention exist, and the present study adds to this knowledge. The degree of participation was quite high as all the invited schools and sixty-one of the seventy-one invited classes participated. The attrition during the follow-up study consisted of two classes with missing follow-up data, one of which did not participate in the follow-up study and the other failed to collect the data successfully. In addition, six classes in the intervention schools had teachers who failed to return the questionnaire on implementation, and therefore these classes were not included in the analyses. This could have influenced the results if the children in these classes differed from the other children. We decided not to include the children from these classes in the analyses as we had no information about the classes' level of implementation. The measurement of implementation could have been more precise: no data on the fidelity to intervention instructions or the implementation of specific lessons exist. A similar type of implementation measure was used in the Pro Children study, which also showed a relationship with achieved effects $^{(15)}$. No other evaluation of the validity of the implementation construct was done, which can be construed as a weakness. Moreover, the study sample was not representative of the whole country, as it was constituted of pupils in Swedish-speaking schools; thus, it could possibly be representative of the Finnish Swedish-speaking minority. About $5 \%$ of Finns are Swedish speaking. Some of Cronbach's $\alpha$ for the mediators were very low. This is partly because only two questions were used for most constructs. This is common when studying children, as the questionnaire can otherwise be too long and demanding. Cronbach's $\alpha$ were quite equal in the validation study carried out in five European countries ${ }^{(19)}$. Another weakness of the study was the use of FFQ data on FV intake. As only intake frequency was studied, we do not know whether changes in portion sizes occurred.

\section{Conclusion}

In the present study, changes in the knowledge of recommendations, liking and bringing fruits to school as a snack were found to act as mediators between the degree of implementation of a school-based intervention and an increase in the frequency of fruit intake. Therefore, the level or degree of implementation of an intervention should be assessed when examining its effect. No effect on the frequency of vegetable intake was found. Future intervention studies should concentrate on increasing vegetable intake and invest in the implementation of interventions.

\section{Acknowledgements}

The authors cordially thank all the teachers and children who participated in the study and all the staff and students from the ten participating countries who contributed to the data collection and entry.

The PRO GREENS project has been made possible through financial support from the European Commission's Programme of Community Action in the Field of Public Health 2003-8. The study does not necessarily reflect the Commission's views and in no way anticipates its future policy in this area. The Juho Vainio Foundation provided additional financial support to the Finnish study group.

The authors' contributions are as follows: R. L. was responsible for writing the manuscript; S. M. carried out the statistical analyses with the assistance of E. L. and both contributed to the writing of the manuscript; C. R., S. t. V., N. L., I. T., A. Y. and $\mathrm{E}$. R. planned the intervention, initialised and conducted the data collection, and revised the manuscript. All authors read and approved the manuscript.

None of the authors has any conflicts of interest to declare.

\section{References}

1. WHO (2004) Global Strategy on Diet, Physical Activity and Health. Childhood Overweight and Obesity. Geneva: WHO. http://www.who.int/dietphysicalactivity/childhood/en/ed

2. Boeing H, Bechthold A, Bub A, et al. (2012) Critical review: vegetables and fruit in the prevention of chronic diseases. Eur J Nutr 51, 637-663.

3. Delgado-Noguera M, Tort S, Martinez-Zapata MJ, et al (2011) Primary school interventions to promote fruit and vegetable consumption: a systematic review and metaanalysis. Prev Med 53, 3-9.

4. Knai C, Pomerleau J, Lock K, et al. (2006) Getting children to eat more fruit and vegetables: a systematic review. Prev Med 42, 85-95.

5. Evans CE, Christian MS, Cleghorn CL, et al. (2012) Systematic review and meta-analysis of school-based interventions to improve daily fruit and vegetable intake in children aged 5 to 12 y. Am J Clin Nutr 96, 889-901.

6. Van Cauwenberghe E, Maes L, Spittaels H, et al. (2010) Effectiveness of school-based interventions in Europe to promote healthy nutrition in children and adolescents: systematic review of published and 'grey' literature. Br J Nutr $\mathbf{1 0 3}$ 781-797

7. Brug J, Tak NI, te Velde SJ, et al. (2008) Taste preferences, liking and other factors related to fruit and vegetable intakes among schoolchildren: results from observational studies. Br J Nutr 99, Suppl. 1, S7-S14.

8. De Bourdeaudhuij I, te Velde S, Brug J, et al. (2008) Personal, social and environmental predictors of daily fruit and vegetable intake in 11-year-old children in nine European countries. Eur J Clin Nutr 62, 834-841.

9. Neumark-Sztainer D, Wall M, Perry C, et al. (2003) Correlates of fruit and vegetable intake among adolescents. Findings from Project EAT. Prev Med 37, 198-208.

10. Ray C, Roos E, Brug J, et al. (2012) Role of free school lunch in the associations between family-environmental factors and children's fruit and vegetable intake in four European countries. Public Health Nutr 16, 1109-1117.

11. van Stralen MM, Yildirim M, te Velde SJ, et al. (2011) What works in school-based energy balance behaviour 
interventions and what does not? A systematic review of mediating mechanisms. Int J Obes (Lond) 35, 1251-1265.

12. Durlak JA \& DuPre EP (2008) Implementation matters: a review of research on the influence of implementation on program outcomes and the factors affecting implementation. Am J Community Psychol 41, 327-350.

13. McGraw SA, Sellers D, Stone E, et al. (2000) Measuring implementation of school programs and policies to promote healthy eating and physical activity among youth. Prev Med 31, S86-S97.

14. Bessems KM, van Assema P, Crutzen R, et al. (2012) Examining the relationship between completeness of teachers implementation of the Krachtvoer healthy diet programme and changes in students' dietary intakes. Public Health Nutr 16, 1273-1280.

15. Wind M, Bjelland M, Perez-Rodrigo C, et al. (2008) Appreciation and implementation of a school-based intervention are associated with changes in fruit and vegetable intake in 10- to 13-year old schoolchildren - thePro Children study. Health Educ Res 23, 997-1007.

16. Brug J, Yngve A \& Klepp KI (2005) The pro children study: conceptualization, baseline results and intervention development of a European effort to promote fruit and vegetable consumption in schoolchildren. Ann Nutr Metab 49, 209-211.

17. Bartholomew LK, Parcel GS, Kok G, et al. (2006) Planning Health Promotion Programs. An Intervention Mapping Approach. San Francisco, CA: Jossey Bass.

18. Haraldsdottir J, Thorsdottir I, de Almeida MD, et al. (2005) Validity and reproducibility of a precoded questionnaire to assess fruit and vegetable intake in European 11- to 12-year-old schoolchildren. Ann Nutr Metab 49, 221-227.

19. De Bourdeaudhuij I, Klepp KI, Due P, et al. (2005) Reliability and validity of a questionnaire to measure personal, social and environmental correlates of fruit and vegetable intake in 10-11-year-old children in five European countries. Public Health Nutr 8, 189-200.

20. Lynch C, Kristjansdottir AG, te Velde SJ et al. (2014) Fruit and vegetable consumption in a sample of 11 -year-old children in ten European countries - the PRO GREENS cross-sectional survey. Public Health Nutr (epublication ahead of print version 15 July 2014).

21. Muthén LK \& Muthén BO (1998-2012) Mplus User's Guide, 7th ed. Los Angeles, CA: Muthén \& Muthén.

22. Currie C, Gabhainn SN, Godeau E, et al. (editors) (2008) Inequalities in Young People's Health: Health Behaviour in School-Aged Children. International Report from the 2005/ 2006 Survey. Health Policy for Children and Adolescents, 5th ed. Copenhagen: World Health Organisation, Regional Office for Europe.

23. Story M, Mays RW, Bishop DB, et al. (2000) 5-a-day Power Plus: process evaluation of a multicomponent elementary school program to increase fruit and vegetable consumption. Health Educ Behav 27, 187-200.

24. Durlak JA (2010) The importance of doing well in whatever you do: a commentary on the special section, "Implementation research in early childhood education". Early Child Res Quart 25, 348-357.

25. Reynolds KD, Bishop DB, Chou CP, et al. (2004) Contrasting mediating variables in two 5-a-day nutrition intervention programs. Prev Med 39, 882-893.

26. Amaro S, Viggiano A, Di Costanzo A, et al. (2006) Kaledo, a new educational board-game, gives nutritional rudiments and encourages healthy eating in children: a pilot cluster randomized trial. Eur J Pediatr 165, 630-635.

27. Reynolds KD, Yaroch AL, Franklin FA, et al. (2002) Testing mediating variables in a school-based nutrition intervention program. Health Psychol 21, 51-60.

28. Campbell MK, McLerran D, Turner-McGrievy G, et al. (2008) Mediation of adult fruit and vegetable consumption in the National 5 A Day for Better Health community studies. Ann Behav Med 35, 49-60.

29. Tak NI, Te Velde SJ \& Brug J (2008) Are positive changes in potential determinants associated with increased fruit and vegetable intakes among primary schoolchildren? Results of two intervention studies in the Netherlands: the Schoolgruiten Project and the Pro Children Study. Int J Behav Nutr Phys Act 5, 21. 